\title{
Associação entre polimorfismos genéticos na enzima metilenotetrahidrofolato redutase e avaliação de qualidade de vida em pacientes em uso do antineoplásico oral capecitabina
}

\author{
João Carlos C. Teixeira*, Natalia da C. Duarte, Mariana R. B. Medeiros, Thiago S. Cobaxo, Rafael N. de Souza, \\ Carmen S. P. Lima, Patricia Moriel
}

\begin{abstract}
Resumo
A capecitabina, medicamento antineoplásico de uso oral amplamente utilizado no tratamento de tumores colorretais e gástricos, embora opção terapêutica efetiva, apresenta altas taxas de toxicidade. O presente trabalho teve como objetivo correlacionar a variante genética rs1801133 da enzima metilenotetrahidrofolato redutase com a qualidade de vida anterior e posterior ao tratamento de pacientes em uso de capecitabina no Ambulatório de Oncologia do Hospital de Clínicas/UNICAMP. Foram incluídos 109 pacientes, predominantemente do sexo masculino, com média de idade de $58,61 \pm 10,74$. O genótipo foi determinado através da técnica de PCR-real time e a qualidade de vida avaliada por formulários que estão de acordo com os protocolos adotados pela European Organisation for Research and Treatment of Cancer, EORTC. Não foram observadas correlações entre a variante genética em questão e a qualidade de vida dos pacientes.
\end{abstract}

\section{Palavras-chave:}

capecitabina, qualidade de vida, polimorfismo.

\section{Introdução}

A capecitabina é um medicamento antineoplásico de uso oral utilizado na terapêutica para câncer colorretal e gástrico e está disponível no Sistema Único de Saúde (SUS). Apresenta altas taxas de toxicidade, porém é utilizado amplamente por ser opção efetiva. É sabido, por estudos de farmacogenômica, que há uma correlação entre a eficácia de fármacos e a toxicidade baseada em variações do genoma do paciente. A partir das taxas de toxicidade apresentadas pelo medicamento e do conhecimento de fatores intrínsecos ao paciente, que podem proporcionar a variação dos efeitos adversos, se faz necessária a avaliação da qualidade de vida, descrita como sendo a "percepção de vida, valores, objetivos, padrões e interesses no âmbito da cultura por parte de um indivíduo", para analisar o impacto do tratamento no bem-estar do paciente. Este estudo teve como objetivo correlacionar a variante genética rs1801133 da enzima metilenotetrahidrofolato redutase com a qualidade de vida anterior e posterior ao tratamento de pacientes em uso de capecitabina no Ambulatório de Oncologia do Hospital de Clínicas/UNICAMP.

\section{Resultados e Discussão}

Foram observadas diferenças significativas nos parâmetros avaliados pelo questionário EORTC QLQC30 (qualidade de vida geral) em dois domínios principais, sendo eles a "função social" que aumentou de $90,3 \%$ para $96,5 \%$ após o terceiro ciclo de tratamento, e "dor" que foi frequente em $22,8 \%$ dos pacientes antes do tratamento e $12,1 \%$ após o terceiro ciclo de tratamento, sendo uma redução satisfatória dadas as condições dos pacientes. A frequência alélica da variante determinada, exibida na figura 1 , se apresentou de acordo com o descrito na literatura. Embora diversos estudos correlacionando variantes genéticas e qualidade de vida do paciente venham ganhando espaço no cenário atual, a literatura que possivelmente corresponderia com o presente estudo se apresentou escassa, não tratando de pacientes com câncer colorretal ou gástrico em si ou sequer mencionando estudos envolvendo a capecitabina, e o número de pacientes para a realização da análise no estudo se apresentou abaixo do esperado, dificultando o trabalho dos dados que exibiriam resultados conclusivos.

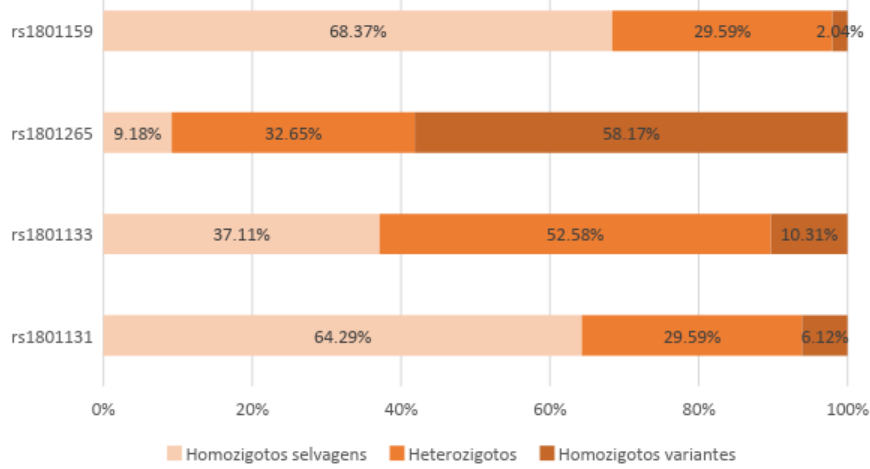

Figura 1. Frequência alélica das variantes genéticas de DYPD (rs1801159 e rs1801265) e MTHFR (rs1801133 e rs1801131) em pacientes com câncer colorretal e gástrico, tratados com capecitabina no Hospital de Clínicas da UNICAMP, em 2017 e 2018.

\section{Conclusões}

O estudo apresentou resultados significativos a partir do monitoramento dos pacientes ao longo dos ciclos de tratamento, comprovando a relevância dos dados da literatura no que diz respeito à qualidade de vida e frequência populacional de alelo variante, entretanto não foram observadas associações entre a qualidade de vida dos pacientes e a variante genética estudada.

\section{Agradecimentos}

Ao CNPq, pelo apoio financeiro do projeto, a todos os pacientes que se dispuseram a participar da pesquisa, a minha família e a equipe do LAFFAC. 